\title{
Evaluación de un sistema de tratamiento de aguas residuales no domésticas para la remoción de carga orgánica en industria de bebidas no alcohólicas ${ }^{1}$
}

\section{Evaluation of a non-domestic wastewater treatment system for the removal of organic cargo in the non-alcoholic beverage industry}

\author{
F. Velasco, A. Molano y L. Pramparo
}

Recibido: septiembre 10 de 2018 - Aceptado: septiembre 30 de 2019

\begin{abstract}
Resumen - Este artículo presenta la evaluación de un sistema de tratamiento de aguas residuales perteneciente a la industria manufacturera de bebidas no alcohólicas, carbonatadas y no carbonatadas. El desarrollo de este estudio se llevó a cabo mediante 3 muestreos realizados en los meses de mayo, julio y octubre (donde las operaciones de mantenimiento y limpieza del sistema fueron ejecutadas en julio con el propósito de observar sus implicaciones en octubre) y se muestrearon 6 puntos diferentes de la planta de tratamiento. De las muestras obtenidas se determinó la información INSITU, la presencia de bionutrientes, las características físicas, químicas y los parámetros DBO y DQO, en pro de interpretar su rendimiento en términos de remoción de carga orgánica contaminante y establecer los parámetros de control exigidos por la normativa legal vigente del país para identificar las problemáticas existentes en el sistema, sus posibles causas y el planteamiento de una recomendación como solución teórica de las irregularidades observadas. Se evidenció que la fase de pretratamiento cuenta con un buen desempeño en el desarrollo de las actividades de tratamiento debido a su estabilidad en la temperatura y pH, sin embargo, la generación de lodo residual en esta fase comprende un problema que impacta directamente en el costo de operación y mantenimiento del sistema de tratamiento. El efluente de la planta de producción demostró que la adición de
\end{abstract}

${ }^{1}$ Producto derivado del proyecto ING-2373 financiado por la Vicerrectoría de Investigaciones de la Universidad Militar Nueva Granada.

F. Velasco, Universidad Militar Nueva Granada, Bogotá, Colombia, email: u1101930@unimilitar.edu.co.

A. Molano, Universidad Militar Nueva Granada, Bogotá, Colombia, email: andres.molano@unimilitar.edu.co

L. Pramparo Universidad Militar Nueva Granada, Bogotá, Colombia, laura.pramparo@unimilitar.edu.co

Como citar este artículo: Velasco, F., Molano, A., y Pramparo, L. Evaluación de un sistema de tratamiento de aguas residuales no domésticas para la remoción de carga orgánica en industria de bebidas no alcohólicas, Entre Ciencia e Ingeniería, vol. 13, no. 26, pp. 17-26, julio-diciembre 2019. DOI: https://doi.org/10.31908/19098367.1150.

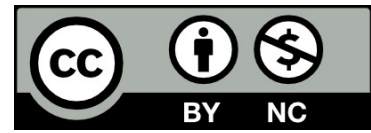

Attribution-NonCommercial 4.0 Intenational (CC By-NC 4.0) agentes químicos y la tasa de generación de lodo activado frente a las condiciones aerobias del sistema, son el mayor apoyo con el que cuenta la planta para realizar los procesos de degradación en la materia orgánica. La caracterización fisicoquímica de las aguas residuales contribuyó a determinar si los mecanismos pertenecientes al tren de tratamiento desarrollaban sus operaciones unitarias bajo condiciones eficientes para la reducción de carga orgánica. Gracias a lo observado en este estudio, sería beneficioso para el sistema la implementación de estructuras complementarias al tanque homogeneizador y tanque ecualizador, para la reducción en la producción de lodo residual, puesto que este problema al acarrearse desde las estructuras iniciales del tren de tratamiento conlleva a la pérdida de eficiencia en los procesos subsecuentes a este durante todo el sistema.

Palabras clave- Aguas residuales no domésticas (ARnD), carga orgánica, DBO, DQO.

Abstract- The document presented here corresponds to the evaluation of a wastewater treatment system belonging to the manufacturing industry of carbonated and non-carbonated soft drinks. The development of this study was performed through 3 samplings carried out in the months of May, July and October (where the maintenance and cleaning operations of the system were carried out in July with the purpose of observing their implications in October) and 6 different points of the treatment plant were sampled. From the obtained samples, the insitu information was determined, the presence of bionutrients, the physical and chemical characteristics, and the BOD and COD parameters, in order to interpret their performance in terms of removal of contaminating organic load, and establish the control parameters required by the current legal regulations of the country to identify the problems existing in the system, their possible causes and the approach of a recommendation as a theoretical solution to the irregularities observed. It was evidenced that the pretreatment phase has a good performance in the development of treatment activities due to its stability in temperature and $\mathrm{pH}$; however, the generation of residual sludge in this phase comprises a problem that directly impacts on the cost of operation and maintenance of the treatment system. The effluent from the production plant showed that the addition of chemical agents and the generation rate of activated sludge against the aerobic conditions of the system are the greatest support that the plant has to perform the processes of degradation in organic 
matter. The physicochemical characterization of the wastewater helped determine whether the mechanisms belonging to the treatment train developed their unit operations under efficient conditions for the reduction of organic load. Thanks to what was observed in this study, it would be beneficial for the system to implement complementary structures to the homogenizer tank and equalizer tank, for the reduction in the production of residual sludge, since this problem when being carried from the initial structures of the treatment train entails to the loss of efficiency in the subsequent processes to this throughout the system.

Key-Word- Non-domestic wastewater (nDWW), organic load, BOD, COD.

\section{INTRODUCCIÓN}

$\mathrm{D}$ urante la última década, debido a la concentración de la población en zonas urbanas ha aumentado la presión de las ciudades sobre los recursos naturales, la dotación de vivienda y la prestación de servicios públicos (agua, saneamiento básico, energía, etc.). Esto ha intensificado las problemáticas ambientales, entre las que se destaca la contaminación del recurso hídrico generada por la descarga de las aguas residuales no tratadas provenientes de los alcantarillados municipales [1]. En general, el tratamiento de aguas en Colombia se encuentra normalizado por la resolución 0631 del año 2015, dentro de la cual encontramos los parámetros máximos y mínimos permisibles en todos los sectores contribuyentes al aumento de carga orgánica dentro de las fuentes hídricas y las conexiones hidrosanitarias con los colectores en alcantarillados públicos.

Generalmente, todas las actividades domésticas e industriales generan residuos; en consecuencia, es responsabilidad por parte de estos sectores acoplarse a la respectiva legislación que para tal efecto rige en los países [2]. Los sectores industriales comprendidos en la normativa colombiana corresponden a las actividades productivas de agroindustria y ganadería, actividades de minería, actividades de hidrocarburos, actividades de fabricación y manufactura de bienes, y las actividades de elaboración de productos alimenticios y bebidas. En este último sector, la resolución distingue entre la elaboración de productos alimenticios, alimentos preparados para animales, maltas y cervezas, y la producción de bebidas no alcohólicas, aguas minerales y otro tipo de aguas embotelladas.

El tratamiento de aguas residuales urbanas es una combinación de procesos que genera grandes volúmenes de lodos orgánicos altamente putrescibles [2]. Debido a esto, la tecnología requerida para desarrollar los procesos de tratamiento que contribuyen a la reducción en la producción de carga orgánica y lodo residual se puede dividir en dos tipos, (a) Reducción de lodos, en línea de tratamiento de aguas y (b) Reducción en la producción de lodos, en línea del tratamiento de lodos residuales [3]. La capacidad receptora de los sistemas de tratamiento se encuentra determinada por los valores máximos permisibles de la legislación colombiana, por esta razón, las PTAR (Planta de Tratamiento de Aguas Residuales) desarrollan sus operaciones unitarias simultáneamente en estructuras hidráulicas, mediante procesos físicos, químicos y biológicos.
En el caso de la elaboración de bebidas no alcohólicas, aguas minerales y otro tipo de aguas embotelladas, es importante conocer los procesos de producción para estimar el contenido de materia orgánica y microrganismos contribuyentes a la contaminación en el agua residual de la industria. Según el estudio realizado en [4], el proceso se resume en 4 pasos:

\section{1) Tratamiento de Agua para Elaboración de Bebidas}

El agua es tomada desde un pozo profundo, la cual es tratada con el fin de eliminar microorganismos y oxidar potencialmente la materia orgánica, con la finalidad de ser dirigida hacia 3 tipos de tratamiento:

a) Tratamiento multibarrera (agua usada en la preparación de jarabes).

b) Tratamiento de ablandamiento (agua para enjuague de envases).

c) Osmosis inversa (para agua envasada).

\section{2) Tratamiento Multibarrera}

El agua cruda es bombeada a la cisterna, desde la cual es enviada hacia los floculadores (reactores) donde se disminuye la alcalinidad del agua mediante la adición de cal (óxido de calcio hidratado) y el uso de sulfato férrico para provocar la precipitación de elementos insolubles.

\section{3) Ósmosis Inversa}

El agua cruda se somete a un proceso de filtración molecular donde se retienen el mayor porcentaje de sales disueltas y materia orgánica.

\section{4) Preparación de Jarabes}

El proceso empieza con la preparación del jarabe simple, al cual posteriormente se le añaden sustancias específicas de acuerdo con el tipo de bebida para conseguir el jarabe terminado. La preparación del jarabe simple inicia con la adición de azúcar en dos grandes tolvas con agua tratada, polvo ayuda filtro y carbón activado. Posteriormente, el jarabe simple es mezclado con saborizantes, acidulantes y preservantes según el tipo de bebida que esté en producción, bajo las especificaciones de la marca. El producto de este proceso se conoce como jarabe terminado. Este jarabe es dirigido a equipos dosificadores que mezclarán el producto con más agua. La mezcla pasa al carbonatador (Bebidas no carbonatadas omiten este paso) dónde se le agrega el anhídrido carbónico $\left(\mathrm{CO}_{2}\right)$ de tipo alimentario, que le incorpora las burbujas necesarias para tener la sensación refrescante propia de las bebidas gaseosas.

Según Azeredo et al. [5] los refrescos regulares contienen aproximadamente $90 \%$ de agua, mientras que los refrescos de dieta contienen hasta un $99 \%$ de agua; tienen $\mathrm{pH}$ marcadamente ácido (2.5-4.0), 1.5 a 4 volúmenes de dióxido de carbono $\left(\mathrm{CO}_{2}\right)$ y un nivel de carbonatación típico de aproximadamente 3 . Sus principales fuentes de contaminación son las levaduras debido a su presencia en zumos de sacarosa y de fruta, así como su capacidad de crecer en ambientes ácidos. En este caso, el deterioro de las levaduras se debe a la producción de $\mathrm{CO}_{2}$ abundante que puede contribuir a problemas como efervescencia excesiva al abrir la botella, 
sedimentos y turbidez. Otra de sus fuentes de contaminación son los hongos filamentosos, éstos pueden presentarse por las ineficientes condiciones higiénicas en el proceso de producción, mala calidad de las materias primas y la contaminación externa proveniente de los envases. En bebidas gaseosas, la pérdida de $\mathrm{CO}_{2}$ de embalaje en PET por un almacenamiento inadecuado, puede promover a la germinación de esporas de hongos filamentosos. Por lo tanto, el embalaje de vidrio y metal proporcionan menos el intercambio de gases [5]. Igualmente, las bacterias productoras de ácido son contribuyentes al deterioro de las bebidas. Generalmente las bacterias ácido-lácticas priman en especies como: Carnobacterium, Enterococcus, Lactococcus, Lactobacillus, Leuconostoc, Pediococcus,Streptococcus, Tetragenococcus, Vagococcus y Weissella. Las bacterias ácido acético que destacan en el deterioro de las bebidas son Acetobacter, Gluconobacter, Gluconoacetobacter y Asaia. Más de la mitad de los contaminantes en las aguas residuales se transforman en lodos residuales [6].

La materia orgánica natural de las aguas residuales es una combinación de carbono, hidrógeno, oxígeno y nitrógeno $(\mathrm{CHON})$ principalmente; con las proteínas (40-60\%), los carbohidratos $(25-50 \%)$ y las grasas y aceites (10\%) como grupos más importantes [7]. En consecuencia, para optimizar los procesos de tratamiento y para controlar la formación de subproductos de desinfección, es vital analizar y caracterizar la materia orgánica natural para una mejor comprensión de sus propiedades y reactividad [8]. Dependiendo de la disposición final del efluente y de la legislación local sobre la calidad mínima de vertimientos puede existir la necesidad de remover la concentración residual de la materia orgánica y de sólidos suspendidos y reducir la concentración de nutrientes y patógenos, mediante el uso de recursos tecnológicos los cuales incluyen procesos biológicos como Lodos Activados, Filtros Percoladores, Lagunas de Oxidación, Humedales y Plantas Acuáticas [9].

El lodo es el residuo producido durante el tratamiento de las aguas residuales [6]. Debido a la reutilización de aguas residuales, los costos de las plantas de tratamiento y de disposición final siguen siendo un factor crítico para el desarrollo del uso sostenible del agua para la industria de alimentos y bebidas [10]. Además, la naturaleza variable de los sustratos industriales, que son muy influenciados por los ciclos estacionales y de producción, complica el estudio de la adaptación del lodo independientemente de las fluctuaciones de carga [11]. Por lo tanto, la digestión de los lodos atrae los intereses investigativos en la mejora de eficiencias de tratamiento y promoción de la reutilización de lodos para reducir su carga [6]. Para facilitar el uso de éstos, se someten a procesos de espesamiento, digestión y deshidratación, adquiriendo así la categoría de Biosólidos [3]. Los biosólidos en Colombia se utilizan en actividades cuya retribución económica subsane la destinación de recursos en el tratamiento de los mismos. Dichas actividades se desarrollan de acuerdo con el decreto 1287 del año 2014, donde se establecen criterios para uso del material generado en plantas de tratamiento de aguas residuales municipales.
El objetivo principal de este estudio es evaluar el sistema de tratamiento de aguas residuales perteneciente a una industria manufacturera de bebidas no alcohólicas, de tal manera que se logre identificar su rendimiento en términos de remoción de carga orgánica contaminante, y determinar posibles problemáticas presentadas durante el proceso de tratamiento. DBO y DQO son los parámetros evaluados y comparados frente a la resolución 631 del año 2015, en pro de estimar si el agua residual efluente de este sistema cumple con los parámetros máximos permisibles establecidos en esta normativa. La finalidad de reconocer cómo trabaja el sistema de tratamiento en términos generales, toma importancia debido a que es una actividad económica contundente en la industria y relevante en el entorno socioeconómico de la marca.

\section{METODOLOGÍA}

\section{A. Características Generales}

El agua residual utilizada para el desarrollo de este proyecto se obtuvo de la PTAR perteneciente a una planta de producción de bebidas no alcohólicas de tipo carbonatadas y no carbonatadas, en la cual se descarga en períodos de una hora las aguas residuales provenientes del lavado de material y desinfección de equipos, limpieza, las descargas sanitarias, y de líneas de producción.

\section{B. Muestreos y caracterización del sistema}

Durante el desarrollo de este estudio los 6 puntos evaluados corresponden a las 5 estructuras propias del tratamiento de aguas y un punto adicional el cual corresponde a la salida, como se muestra en la Fig. 1.

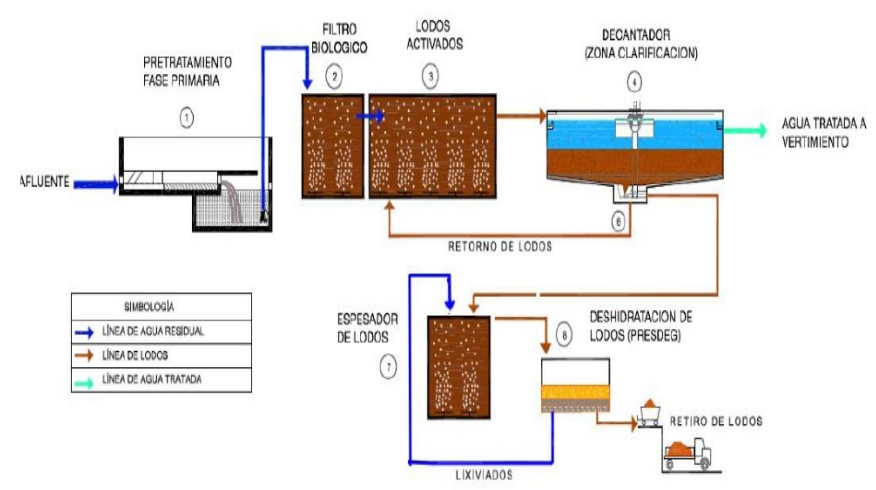

Fig. 1 Diagrama de bloques de la PTAR estudiada.

Mediante 3 muestreos realizados en diferentes períodos del año (mayo, julio y octubre), se evaluaron los 6 puntos del sistema, los cuales corresponden al tanque homogeneizador, tanque ecualizador, filtro biológico, tanque de lodos activados, clarificador y la salida. En el transcurso de los meses mencionados, la planta fue sometida a limpieza y mantenimiento por parte de los operarios, de manera tal que el muestreo 1 se realizó en mayo (antes del mantenimiento), el muestreo 2 en julio (durante el mantenimiento) y el muestreo 3 en octubre (después del mantenimiento).

La PTAR evaluada cuenta con 3 diferentes etapas, siendo 
estas, tanque primario, tanque secundario y tratamiento biológico. La primera etapa corresponde al tanque homogeneizador, el cual regula los caudales entrantes al tren de tratamiento mediante descargas puntuales cada 60 minutos. La segunda etapa comprende un tanque ecualizador, el cual regula las cargas volumétricas por la acción de una serie de trampas de grasas, que sirven como sedimentadores primarios para la remoción de sólidos, en su gran mayoría suspendidos. A este tanque se le inyecta periódicamente dióxido de carbono $\left(\mathrm{CO}_{2}\right)$ y urea $\left(\mathrm{NH}_{3}\right)$ mediante procesos de gasificación, puesto que su función es la de regular las cargas volumétricas del ARnD. El tratamiento biológico es realizado gracias al uso de un filtro biológico y un sistema de lodos activados. El Biofiltro lleva a cabo la remoción de carga orgánica mediante lechos filtrantes los cuales no están en operación de un $100 \%$. El tanque espesador es donde la concentración y volumen de lodos aumenta para ser incorporados al sistema de lodos activados, siendo éste el sustrato con la biomasa correspondiente para la remoción de altos porcentajes de DBO. Para finalizar el tratamiento y remover toda clase de materia orgánica y microorganismos patógenos, el sistema utiliza un Clarificador el cual cuenta con 2 dosificadores para el control del $\mathrm{pH}$ y otros elementos químicos solubles en el ARnD.

El proceso de adquisición de las muestras se desarrolló de acuerdo con el instructivo TI0187 elaborado por el Instituto de Hidrología, Meteorología y Estudios Ambientales - IDEAM. Cada muestreo se realizó por un periodo de siete (7) horas con intervalos de toma de muestra cada 30 minutos, tiempo durante el cual se compuso el volumen de cada muestra en su respectiva botella. La recolección de las muestras de agua se llevó a cabo en frascos de color ámbar de 1 Litro por duplicado, además una alícuota de cinco (5) litros en un recipiente plástico. En la determinación de grasas y aceites, las muestras se envasaron en frascos de vidrio con capacidad de 1 Litro junto a su preservante ácido clorhídrico $2 \mathrm{~N}$. Para la preservación de las muestras de DQO se utilizó ácido sulfúrico al $2 \mathrm{~N}$.

De manera paralela a la obtención de las muestras, en cada uno de los puntos se determinaron parámetros INSITU como sólidos disueltos con el uso de conos de sedimentación Imhoff, además de $\mathrm{pH}$, oxígeno disuelto, temperatura y conductividad eléctrica, siguiendo los lineamientos establecidos en el Standard Methods for the Examination of Water and Wastewater (2017). Además de los parámetros INSITU, los Bionutrientes (Nitratos, Nitritos, Amonio y Fosfato) también fueron determinados bajo los protocolos establecidos en el Standard Methods mediante colorimetría.

Para la determinación de la DBO se usó el método de incubación y electrometría, según el protocolo TP0087 del IDEAM, de la misma manera para DQO se determinó gracias al método de reflujo cerrado y volumetría, bajo el protocolo TP0086 del IDEAM.

El cálculo de la acidez se realizó por medio del método de titulación con $\mathrm{NaOH}$, la alcalinidad mediante el método de titulación con $\mathrm{H}_{2} \mathrm{SO}_{4}$, bajo el protocolo TP0211 del IDEAM; dureza mediante el método de titulación de EDTA, bajo el protocolo TP0341 del IDEAM. Para conocer los valores de aceites y grasas, se utilizó cloroformo como método de determinación.

\section{Capacidad Hidráulica del Sistema}

Según la información recolectada en momentos previos a la ejecución de este proyecto, el caudal total promedio tratado durante $24 \mathrm{hs}$ es de $1900 \mathrm{~m}^{3}$. Las 5 estructuras mencionadas en el apartado II-B presentan una capacidad volumétrica y tiempos de retención hidráulica, como se muestra en la Tabla I.

TABLA I

CAPACIDAD HIDRÁULICA DEL SISTEMA

\begin{tabular}{cccc}
\hline Unidad & Cantidad & Capacidad, $\boldsymbol{C}\left(\boldsymbol{m}^{3}\right)$ & Tiempo de Retención, TRH(hora) \\
\hline \hline Ecualizador & 1 & 396 & 3.66 \\
Homogenizador & 1 & 170 & 1.57 \\
Filtro Biológico & 1 & 677.4 & 6.25 \\
Tanque Lodos Activados & 1 & 2187 & 20.19 \\
Decantador & 1 & 690 & 6.37 \\
\hline \hline
\end{tabular}

\section{RESULTADOS Y DISCUSIÓN}

Toda caracterización de aguas residuales implica un programa de muestreo apropiado para asegurar representatividad de la muestra y un análisis de laboratorio de conformidad con normas estándares que aseguren precisión y exactitud en los resultados [7].

Los parámetros de control exigidos por la normativa legal vigente (resolución 631 del año 2015) se muestran a continuación en la Tabla II.

Teniendo en cuenta los parámetros expuestos en la Tabla II se evaluaron comparativamente con los resultados determinados durante cada muestreo. La importancia de conocer los parámetros exigidos por la normativa colombiana competente, en este caso, se resume en determinar si el sistema evaluado aporta un efluente con condiciones y características favorables para el desarrollo de la vida en el agua.

Durante el desarrollo de este estudio la evaluación de parámetros insitu se llevó a cabo bajo el protocolo IDEAM TI089. La Tabla III presenta de manera resumida los valores de los parámetros insitu en cada una de las estructuras que componen el tren de tratamiento, además del promedio general del parámetro durante todo el estudio. El orden de los resultados corresponde al orden en que fueron evaluados los parámetros en la planta de tratamiento, de manera tal que las columnas corresponden al valor adquirido en el laboratorio y las filas corresponden a cada uno de los puntos evaluados en la planta. Los parámetros insitu corresponden a temperatura, conductividad eléctrica, sólidos disueltos, sólidos sedimentables, y oxígeno disuelto.

La temperatura es un parámetro importante en aguas residuales puesto que afecta y altera la vida acuática, modifica la concentración de saturación de oxígeno disuelto y la velocidad de las reacciones químicas y de la actividad bacteriana [7]. Como observamos en la Tabla III el valor de la temperatura promedio determinada durante el primer muestreo fue de $21.10^{\circ} \mathrm{C}, 21.94^{\circ} \mathrm{C}$ para el segundo muestreo y $21.52^{\circ} \mathrm{C}$ para el tercer muestreo. La temperatura del biofiltro es la menor, y la variabilidad de ésta en el agua durante su paso por 
el tren de tratamiento es poca, arrojando un valor total promedio de temperatura computado de $21.5^{\circ} \mathrm{C}$, con lo cual se mantiene en un rango aceptable para la actividad bacteriana.

TABLA II

VALORES MÁXIMOS PERMISIBLES SEGÚN RESOLUCIÓN 631 DE 2015

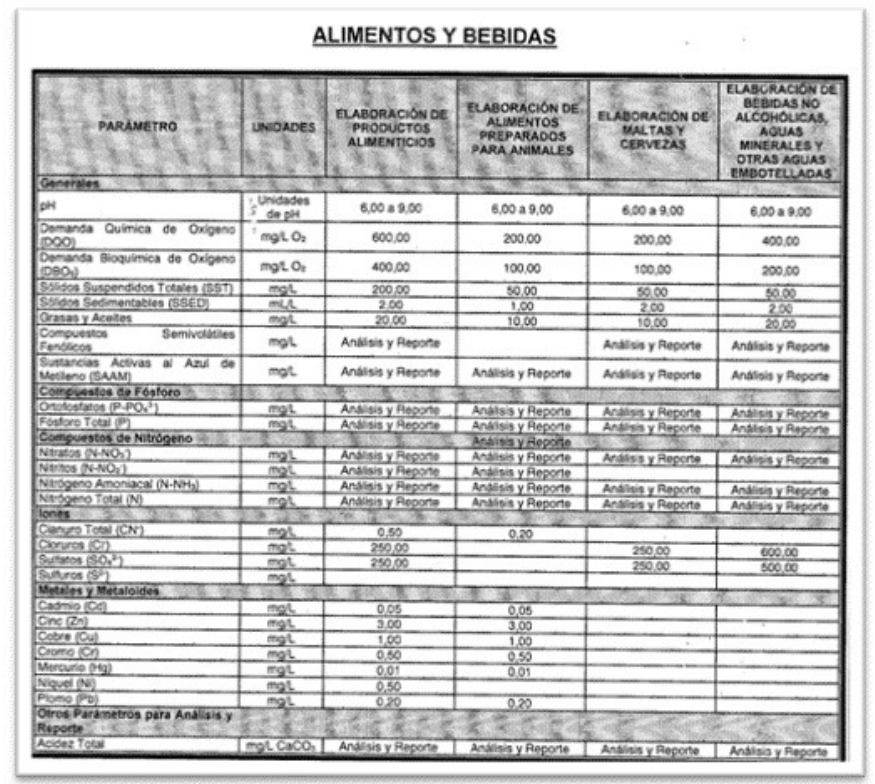

El pH es la medida de la concentración del ion hidrógeno en el agua. En la Tabla III apreciamos que el valor de $\mathrm{pH}$ muestra una baja variabilidad dentro de las 3 pimeras estructuras (homogeneizador, ecualizador y biofiltro), sin embargo, el paso del agua hacia el tanque de lodos activados nos demuestra un incremento en el valor de la medición del $\mathrm{pH}$, el cual se repite durante los 3 muestreos siguientes. La razón por la cual puede presentarse esta variabilidad es debido al proceso de digestión aerobia realizado por el sistema de lodos activados, el cual realiza procesos de oxidación de la materia orgánica.

Según Romero [7], el valor de $\mathrm{pH}$ adecuado para diferentes procesos de tratamiento y para la existencia de la mayoría de la vida biológica puede ser muy restrictivo y crítico, pero generalmente es de 6.5 a 8.5 , lo que pone en evidencia que los parámetros de funcionamiento como lo son la temperatura y el $\mathrm{pH}$ se encuentran dentro de un valor estable.

La conductividad eléctrica, como se muestra en la Tabla III, disminuye progresivamente durante su paso a través del tren de tratamiento, la causa de esta variabilidad radica en que la conductividad depende de la cantidad de sales disueltas presentes en un medio líquido, por ello, a medida que los procesos de tratamiento son llevados a cabo, la resistencia de la solución cambia por ende la medida también. Este patrón de comportamiento de la conductividad eléctrica se repite en los 2 muestreos siguientes.

Los sólidos disueltos representan el material soluble y coloidal que requiere usualmente oxidación biológica, coagulación y sedimentación para su remoción. Concretamente observamos que la medida de sólidos disueltos no presenta ningún patrón de disminución o aumento a medida que el agua pasa por el tren de tratamiento.
TABLA III PARÁMETROS INSITU

\begin{tabular}{|c|c|c|c|c|c|c|}
\hline \multicolumn{7}{|c|}{ Muestreo I INSITU } \\
\hline Punto Muestreado & $\mathrm{T}\left({ }^{\circ} \mathrm{C}\right)$ & pH & $\begin{array}{l}\text { Conductividad, } \\
\text { EC(S/m) }\end{array}$ & $\begin{array}{l}\text { Solidos disueltos, } \\
\text { TSD(ppm) }\end{array}$ & $\begin{array}{l}\text { Solidos } \\
\text { Sedimentables, } \\
\text { TSS(wI/L) }\end{array}$ & $\begin{array}{l}\text { Orígeno Disuelto, } \\
\text { OD(mgL) }\end{array}$ \\
\hline Homogeneizador & 20.74 & 6.52 & 3.222 & 1.608 & 10.25 & 0.306 \\
\hline Ecualizador & 23.14 & 5.15 & 3.552 & 2.38 & 0.375 & 0.078 \\
\hline Bioffitro & 18.92 & 5.50 & 3.124 & 1.566 & 18 & 1.934 \\
\hline Lodos Activados & 20.92 & 7.50 & 3.688 & 1.842 & 787.5 & 1.678 \\
\hline Clarificador & 21.34 & 7.76 & 4.068 & 2.024 & 2.65 & 1.06 \\
\hline & 21.54 & 7.96 & 4.364 & 2.186 & 0 & 3.29 \\
\hline Promedio & 21.10 & 6.73 & 3.67 & 1.93 & 136.46 & 1.39 \\
\hline \multicolumn{7}{|c|}{ Muestreo II INSITU } \\
\hline Punto Muestreado & $\bar{T}\left({ }^{\circ} \mathrm{C}\right)$ & pH & $\begin{array}{l}\text { Conductividad, } \\
\text { EC(S/m) }\end{array}$ & $\begin{array}{l}\text { Solidos disueltos, } \\
\text { TSD(ppm) }\end{array}$ & $\begin{array}{l}\text { Solidos } \\
\text { Sedimentable's, } \\
\text { TSS(mL/L) }\end{array}$ & 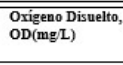 \\
\hline Homogeneizador & 24.067 & 7.58 & 4.093 & 2.063 & 2.200 & 0.32 \\
\hline Ecualizador & 21.133 & 7.05 & 3.367 & 1.680 & 9.700 & 0.12 \\
\hline Biofilitro & 19.733 & 6.67 & 3.170 & 1.587 & 27.000 & 1.19 \\
\hline Lodos Activados & 22.167 & 7.59 & 2.987 & 1.470 & 800.000 & 0.89 \\
\hline Clarificador & 22.200 & 9.68 & 2.363 & 1.283 & 2.000 & 1.29 \\
\hline Salida & 22.367 & 9.07 & 3.047 & 1.527 & 0.033 & 3.14 \\
\hline Promedio & 21.94 & 7.94 & 3.17 & 1.60 & 140.16 & 1.16 \\
\hline \multicolumn{7}{|c|}{ Muestreo III INSITU } \\
\hline Punto Muestreado & $\bar{T}\left({ }^{\circ} \mathrm{C}\right)$ & pH & $\begin{array}{l}\text { Conductividad, } \\
\text { EC(S/m) }\end{array}$ & $\begin{array}{l}\text { Solidos disueltos, } \\
\text { TSD(ppm) }\end{array}$ & $\begin{array}{l}\text { Solidos } \\
\text { Sedimentables, } \\
\text { TSS(mL/L) }\end{array}$ & $\begin{array}{l}\text { Oxigeno Disuelto, } \\
\text { OD(mg/L) }\end{array}$ \\
\hline Homogeneisador & 22.40 & 7.05 & 3.66 & 1.84 & 6.23 & 0.32 \\
\hline Ecualizador & 22.14 & 6.10 & 3.46 & 2.03 & 5.04 & 0.12 \\
\hline Bieflitro & 19.33 & 6.09 & 3.15 & 1.58 & 22.50 & 1.19 \\
\hline Lodos Activados & 21.54 & 7.55 & 3.34 & 1.66 & 793.75 & 0.89 \\
\hline Clarificador & 21.77 & 8.72 & 3.22 & 1.65 & 2.33 & 1.29 \\
\hline Salida & 21.95 & 8.52 & 3.71 & 1.86 & 0.02 & 3.14 \\
\hline Promedio & 21.52 & 7.34 & 3.42 & 1.77 & 138.31 & 1.16 \\
\hline
\end{tabular}

Los sólidos sedimentables son una medida del volumen de sólidos asentados al fondo de un cono Imhoff, en un período de una hora, y representan la cantidad de lodo removible por sedimentación simple; se expresan comúnmente en $\mathrm{mL} / \mathrm{L}$ [7]. En este estudio el valor más alto de sólidos sedimentables se presenta en el punto 4, que comprende el sistema de lodos activados, donde la medida alcanzó los $800 \mathrm{~mL} / \mathrm{L}$. En este sentido, es lógico obtener un resultado que difiere en gran medida al valor presentado por el resto de las estructuras, debido a que aquí se concentra la eficiencia de tratamiento bajo procesos biológicos que involucran la recirculación de lodos y la depredación bacteriana.

La solubilidad del oxígeno atmosférico, en aguas dulces oscila entre $7 \mathrm{mg} / \mathrm{L}$ a $35^{\circ} \mathrm{C}$ y $14.6 \mathrm{mg} / \mathrm{L}$ a $0^{\circ} \mathrm{C}$ para presión de una atmósfera [7]. Como se observa en la Tabla III, el valor del oxígeno disuelto aumenta a medida que el proceso de tratamiento es ejecutado, lo que indica que la remoción de carga orgánica realizada por las estructuras hidráulicas es eficiente puesto que el oxígeno disuelto (OD) limita la capacidad auto purificadora en los cuerpos de agua. Durante los 3 muestreos se demostró que el valor de oxígeno disuelto en el efluente de la PTAR es superior a $3 \mathrm{mg} / \mathrm{L}$.

\section{Bionutrientes, grasas y aceites en el ARnD}

La determinación de la presencia de bionutrientes en el agua residual permite entender los procesos biológicos realizados por el sistema de tratamiento. Como se expuso en la parte II-B el sistema concentra su mayor importancia en el sistema de lodos activados, puesto que este sistema de tipo biológico realiza procesos de degradación de materia orgánica involucrando bionutrientes y oxígeno. El proceso de lodos activados es un método eficiente de tratamiento de aguas residuales para asegurar un mínimo impacto residual en el medio ambiente; sin embargo, el sistema de lodos activados posee la grave desventaja de producir grandes volúmenes de lodo como desecho [12].

La Tabla IV representa el resumen de los valores obtenidos en cada uno de los puntos clave de la PTAR, en ella se 
aprecian los valores obtenidos para los bionutrientes, en este caso se presentan los valores de nitrógeno en sus 3 formas de interés para aguas residuales, es decir nitrógeno orgánico, nitrógeno amoniacal y nitrógeno de nitritos y nitratos; además se resume de la misma manera los valores de fósforo presente en el agua residual del estudio.

La presencia excesiva de nitrógeno en las aguas residuales ha causado graves alteraciones del ciclo de nutrientes naturales entre el mundo viviente y el suelo, el agua y la atmósfera [13]. Las formas de interés en agua residual son nitrógeno orgánico, nitrógeno amoniacal y nitrógeno de nitritos y nitratos.

Según Romero [7], todas ellas son interconvertibles bioquímicamente y componentes del ciclo del nitrógeno. Según esto, la forma predominante es el nitrógeno amoniacal $\left(\mathrm{NH}_{3}\right)$ y como se observa en la Tabla IV, en el muestreo 1 la forma prevaleciente fue de nitritos, por lo cual se entiende que antes de las operaciones de mantenimiento y limpieza, las bacterias descomponen el nitrógeno amoniacal en nitritos $\left(\mathrm{NO}_{2}\right)$ debido a que en el muestreo 2 (el cual se realizó durante las operaciones de mantenimiento y limpieza) la forma predominante fue de nitratos $\left(\mathrm{NO}_{3}\right)$.

Al igual que el nitrógeno, el fósforo también representa un nutriente de interés en el agua residual, debido a que este nutriente también es encontrado en diferentes formas, las cuales pueden se pueden unir con cationes $y$ formar precipitantes de fósforo, dependiendo del $\mathrm{pH}$ del sistema, la temperatura, la cantidad y el tipo de cationes presentes en el agua residual [14]. Como se observa en la Tabla IV, durante el muestreo 1, el contenido de fósforo se encuentra en niveles bajos, sin embargo, durante el muestreo 2 los niveles de fósforo aumentaron drásticamente. Lo anterior puede presentar una afectación en el agua debido a que las operaciones de mantenimiento y limpieza inciden directamente en los procesos de crecimiento de comunidades microbianas que contribuyen al desarrollo de procesos de tratamiento tipo biológico.

TABLA IV BIONUTRIENTES $\left(\mathrm{NH}_{4}^{+}-\mathrm{NO}_{2}-\mathrm{NO}_{3}-\mathrm{PO}_{4}\right)$

\begin{tabular}{|c|c|c|c|c|c|}
\hline \multicolumn{6}{|c|}{$\frac{\text { BIONUTRIENTES }\left(\mathrm{NH}_{4}{ }^{+}-\mathrm{NO}_{2}-\mathrm{NO}_{3}-\mathrm{PO}_{4}\right)}{\text { Muestreo I Bionutrientes }}$} \\
\hline Punto Muestreado & $\begin{array}{l}\text { Nitritos, } \\
\mathrm{NO}_{2} \text { (mg/L) }\end{array}$ & $\begin{array}{l}\text { Nitratos, } \\
\mathrm{NO}_{3}(\mathrm{mg} / \mathrm{L})\end{array}$ & $\begin{array}{l}\text { Amoniaco, } \\
\mathrm{NH}_{3}(\mathrm{mg} / \mathrm{L})\end{array}$ & $\begin{array}{l}\text { Carga total de fosforo, } \\
\mathrm{PO}_{4}(\mathrm{mg} / \mathrm{L})\end{array}$ & Sulfatos, $\mathrm{SO}_{4}(\mathrm{mg} / \mathrm{L})$ \\
\hline Ecualizador & 32.8 & 2 & 280 & 2 & 280 \\
\hline Homogeneizador & 32.8 & 1 & 310 & 1 & 310 \\
\hline Biofiltro & 32.8 & 1 & 340 & 1 & 340 \\
\hline Lodos Activados & 32.8 & 2 & 340 & 2 & 340 \\
\hline Clarificador & 32.8 & 5 & 370 & 5 & 370 \\
\hline Salida & 32.8 & 5 & 550 & 5 & 550 \\
\hline Promedio & 32.80 & 2.67 & 365.00 & 2.67 & 365.00 \\
\hline \multicolumn{6}{|c|}{ Muestreo II Bionutrientes } \\
\hline Punto Muestreado & $\begin{array}{l}\text { Nitritos, } \\
\mathrm{NO}_{2}(\mathrm{mg} / \mathrm{L})\end{array}$ & $\begin{array}{l}\text { Nitratos, } \\
\mathrm{NO}_{3}(\mathrm{mg} / \mathrm{L})\end{array}$ & $\begin{array}{l}\text { Amoniaco, } \\
\mathrm{NH}_{3}(\mathrm{mg} / \mathrm{L})\end{array}$ & $\begin{array}{l}\text { Carga total de fosforo, } \\
\mathrm{PO}_{4}(\mathrm{mg} / \mathrm{L})\end{array}$ & Sulfatos, $\mathrm{SO}_{4}(\mathrm{mg} / \mathrm{L})$ \\
\hline Ecualizador & 1 & 10 & N.D & 50 & N.D \\
\hline Homogeneizador & 1 & 10 & N.D & 50 & N.D \\
\hline Biofiltro & 1 & 10 & N.D & 50 & N.D \\
\hline Lodos Activados & 1 & 10 & N.D & 50 & N.D \\
\hline Clarificador & 0.656 & 44.3 & N.D & 5 & N.D \\
\hline Salida & 0.656 & 88.6 & N.D & 5 & N.D \\
\hline Promedio & 0.89 & 28.82 & & 35.00 & \\
\hline \multicolumn{6}{|c|}{ Muestreo III Bionutrientes } \\
\hline Punto Muestreado & $\begin{array}{l}\text { Nitritos, } \\
\mathrm{NO}_{2}(\mathrm{mg} / \mathrm{L})\end{array}$ & $\begin{array}{l}\text { Nitratos, } \\
\mathrm{NO}_{3}(\mathrm{mg} / \mathrm{L})\end{array}$ & $\begin{array}{l}\text { Amoniaco, } \\
\mathrm{NH}_{3}(\mathrm{mg} / \mathrm{L})\end{array}$ & $\begin{array}{l}\text { Carga total de fosforo, } \\
\mathrm{PO}_{4}(\mathrm{mg} / \mathrm{L})\end{array}$ & Sulfatos, $\mathrm{SO}_{4}(\mathrm{mg} / \mathrm{L})$ \\
\hline Ecualizador & 1 & 10 & N.D & 50 & N.D \\
\hline Homogeneizador & 1 & 10 & N.D & 50 & N.D \\
\hline Biofiltro & 1 & 10 & N.D & 50 & N.D \\
\hline Lodos Activados & 1 & 10 & N.D & 50 & N.D \\
\hline Clarificador & 0.656 & 44.3 & N.D & 5 & N.D \\
\hline Salida & 0.656 & 88.6 & N.D & 5 & N.D \\
\hline Promedio & 0.89 & 28.82 & & 35.00 & \\
\hline
\end{tabular}

La estimación de grasas y aceites es fundamental para determinar la composición de la materia orgánica natural que se encuentre en el agua residual tratada. La Tabla $\mathrm{V}$ expone los resultados obtenidos durante cada muestreo.

TABLA V GRASAS Y ACEITES

\begin{tabular}{|c|c|}
\hline \multicolumn{2}{|c|}{ Muestreo I } \\
\hline Punto Muestreado & $\begin{array}{l}\text { Grasas y Aceites, } \\
(\mathrm{mg} / \mathrm{L})\end{array}$ \\
\hline Homogeneizador & 3.845 \\
\hline Ecualizador & 0.4329 \\
\hline Biofiltro & -0.1868 \\
\hline Lodos Activados & 35.0595 \\
\hline Clarificador & 115.4058 \\
\hline $\begin{array}{l}\text { Salida } \\
\text { S }\end{array}$ & 0.6504 \\
\hline Promedio & 25.8678 \\
\hline \multicolumn{2}{|c|}{ Muestreo II } \\
\hline Punto Muestreado & $\begin{array}{l}\begin{array}{l}\text { Grasas y Aceites, } \\
(\mathrm{mg} / \mathrm{L})\end{array} \\
\end{array}$ \\
\hline Homogeneizador & 10.366 \\
\hline Ecualizador & 3.2836 \\
\hline Biofiltro & $\begin{array}{l}-6.4187 \\
54.6036\end{array}$ \\
\hline $\begin{array}{l}\text { Lodos Activados } \\
\text { Clarificador }\end{array}$ & $\begin{array}{l}-54.6036 \\
-10.6559\end{array}$ \\
\hline Salida & -3.4129 \\
\hline Promedio & -10.24025 \\
\hline \multicolumn{2}{|c|}{ Muestreo III } \\
\hline Punto Muestreado & $\begin{array}{l}\text { Grasas y Aceites, } \\
(\mathrm{mg} / \mathrm{L})\end{array}$ \\
\hline Homogeneizador & 3.0219 \\
\hline Ecualizador & 0.0434 \\
\hline Biofiltro & 0.0398 \\
\hline Lodos Activados & 0.0203 \\
\hline Clarificador & 0.0262 \\
\hline Salida & 0.0295 \\
\hline Promedio & 0.53018333 \\
\hline
\end{tabular}

La determinación de grasas y aceites durante este estudio presentó datos atípicos de valor negativo. Debido a lo anterior, para la interpretación de los valores de grasas y aceites en cada una de las estructuras solo se tomó como válida la información de los muestreos 1 y 3 .

De acuerdo con lo que se observa en la Tabla V, el contenido de aceites y grasas en el muestreo 1 se encuentra demasiado alto, sus valores se resaltan con negrilla puesto que los mismos difieren en gran mayoría de los parámetros exigidos por la normativa del país (ver Tabla 2). Sin embargo, la acción mecánica de las operaciones de limpieza y mantenimiento realizadas al tren de tratamiento demuestran que son un mecanismo que contribuye al aumento de eficiencia en los sistemas de tratamiento, como se aprecia en los datos adquiridos de grasas y aceites durante el muestreo 3. Recordemos que la materia orgánica presente en el agua residual contiene aproximadamente $10 \%$ de grasas y aceites, por lo que se entiende que un aumento o disminución de este parámetro tiene incidencias directas en el funcionamiento de la planta, puesto que al contener grasas y aceites la materia orgánica requiere de diferentes procesos para ser degradada, por lo cual es lógico pensar que al contener más grasa y aceite, es mucho más difícil degradar la materia, en consecuencia habrá una disminución en la eficiencia de las estructuras que componen el tren de tratamiento.

\section{E. Caracterización Fisicoquímica}

Aunque existen caracterizaciones típicas de aguas residuales, las cuales son muy importantes como referencia de 
los parámetros de importancia por analizar y de su magnitud, hay que recordar que cada agua residual es única en sus características, y que los parámetros de polución deben evaluarse en el laboratorio para cada agua residual en específico [7].

TABLA VI

CARACTERÍSTICAS FISICOQUIIMICAS DEL AGUA RESIDUAL

\begin{tabular}{|c|c|c|c|c|c|c|}
\hline \multicolumn{7}{|c|}{ Muestreo I } \\
\hline $\begin{array}{l}\text { Punto } \\
\text { Muestreado }\end{array}$ & $\begin{array}{l}\text { Turbiedad, } \\
\text { (UNT) }\end{array}$ & $\begin{array}{l}\text { Color, } \\
\text { (UPC) }\end{array}$ & $\begin{array}{l}\text { Solidos suspendidos, } \\
\text { SST }(\mathrm{mg} / \mathrm{L} \text { ) }\end{array}$ & $\begin{array}{l}\text { Dureza, } \\
(\mathrm{mg} / \mathrm{L})\end{array}$ & $\begin{array}{l}\text { Acidez, } \\
(\mathrm{mg} / \mathrm{L})\end{array}$ & $\begin{array}{l}\text { Alcalinidad, } \\
(\mathrm{mg} / \mathrm{L})\end{array}$ \\
\hline Homogeneizador & 104.00 & 225.00 & 0.80 & 3.2 & 149.6 & 360 \\
\hline Ecualizador & 153.00 & 225.00 & 0.80 & 3.2 & 113.2 & 280 \\
\hline Biofiltro & 271.00 & 225.00 & 0.75 & 3.4 & 104.2 & 104.2 \\
\hline Lodos Activados & 149.00 & 223.00 & 3.20 & 3.6 & 199.6 & 199.6 \\
\hline Clarificador & 14.15 & 75.00 & 0.75 & 1.76 & 146.8 & 146.8 \\
\hline Salida & 5.32 & 60.00 & 0.00 & 0.952 & 164.6 & 164.6 \\
\hline Promedio & 116.08 & 172.17 & 1.05 & 2.69 & 146.33 & 209.20 \\
\hline \multicolumn{7}{|c|}{ Muestreo II } \\
\hline $\begin{array}{l}\text { Punto } \\
\text { Muestreado }\end{array}$ & $\begin{array}{l}\text { Turbiedad, } \\
\text { (UNT) }\end{array}$ & $\begin{array}{l}\text { Color, } \\
\text { (UPC) }\end{array}$ & $\begin{array}{l}\text { Solidos suspendidos, } \\
\text { SST(mg/L) }\end{array}$ & $\begin{array}{l}\text { Dureza, } \\
(\mathrm{mg} / \mathrm{L})\end{array}$ & $\begin{array}{l}\text { Acidez, } \\
(\mathrm{mg} / \mathrm{L})\end{array}$ & $\begin{array}{l}\text { Alcalinidad, } \\
(\mathrm{mg} / \mathrm{L})\end{array}$ \\
\hline Homogeneizador & 97.33 & 60 & 2.774 & 9.184 & 12.4 & 11.6 \\
\hline Ecualizador & 95.6 & 60 & 3.956 & 14.6 & 10.4 & 9.6 \\
\hline Biofiltro & 169.33 & 50 & 2.862 & 0 & 9.6 & 8.4 \\
\hline Lodos Activados & 571 & 150 & 10.003 & 0 & 12 & 14 \\
\hline Clarificador & 16.11 & 150 & 1.742 & 0 & 8.8 & 9 \\
\hline Salida & 4.02 & 150 & 1.649 & 0 & 10 & 10 \\
\hline Promedio & 158.90 & 103.33 & 3.83 & 3.96 & 10.53 & 10.43 \\
\hline \multicolumn{7}{|c|}{ Muestreo III } \\
\hline $\begin{array}{l}\text { Punto } \\
\text { Muestreado }\end{array}$ & $\begin{array}{l}\text { Turbiedad, } \\
\text { (UNT) }\end{array}$ & $\begin{array}{l}\text { Color, } \\
\text { (UPC) }\end{array}$ & $\begin{array}{l}\text { Solidos suspendidos, } \\
\text { SST(mg/L) }\end{array}$ & $\begin{array}{l}\text { Dureza, } \\
\text { (mg/L) }\end{array}$ & $\begin{array}{l}\text { Acidez, } \\
(\mathrm{mg} / \mathrm{L})\end{array}$ & $\begin{array}{l}\text { Alcalinidad, } \\
(\mathrm{mg} / \mathrm{L})\end{array}$ \\
\hline Homogeneizador & 97.33 & 60 & 2.774 & 0.75 & 1.1 & 10.15 \\
\hline Ecualizador & 95.6 & 60 & 3.956 & 1.6 & 0.65 & 24.1 \\
\hline Biofiltro & 169.33 & 50 & 2.862 & 1.9 & 2.95 & 10.7 \\
\hline Lodos Activados & 571 & 150 & 10.003 & 0.35 & & 21.9 \\
\hline Clarificador & 16.11 & 150 & 1.742 & 1.5 & 5.05 & 11.2 \\
\hline Salida & 4.02 & 150 & 1.649 & 0.35 & 5.7 & 10.75 \\
\hline Promedio & 158.90 & 103.33 & 3.83 & 1.08 & 3.24 & 14.80 \\
\hline
\end{tabular}

La Tabla VI corresponde al resumen de los parámetros que describen las características físicas y químicas del agua residual utilizada en este estudio que corresponden a Turbiedad, Color, Sólidos Suspendidos, Dureza, Acidez y Alcalinidad.

Según Arboleda [15] la turbiedad es la capacidad de un líquido de diseminar un haz luminoso, puede deberse a partículas de arcilla provenientes de la erosión del suelo, crecimientos bacterianos, carga orgánica natural o algas. Para Wen et al. [16] hay dos tipos principales de transductores de turbidez. El primer tipo es el transductor de turbidez nefelométrica, el cual mide la luz dispersa en un cierto ángulo relativo al haz incidente. El segundo se basa, en el método de transmisión y mide la atenuación de la luz.

El color está constituido por sustancias químicas, la mayoría de las veces provenientes de la degradación de la materia orgánica. Como se aprecia en la Tabla VI, los valores obtenidos durante el muestreo 1 presentan una gran diferencia con respecto a los datos presentados en el muestreo 2 y 3 . Además de lo anterior, es importante analizar que el valor de color en el agua, una vez entra al sistema de lodos activados, aumenta de manera tal que las estructuras subsecuentes a este sistema se ven afectadas. Claramente las operaciones de mantenimiento y limpieza en el sistema contribuyen de manera positiva, sin embargo, no es eficiente al observar que el color aumenta en gran medida durante el proceso biológico de tratamiento, con lo cual se disminuye la capacidad del decantador (clarificador) al recibir mayor carga de lo estimado.

Dentro del conglomerado de datos mostrados en la Tabla VI, también encontramos los valores de dureza, acidez y alcalinidad, los cuales denotan las características químicas del agua residual. La dureza es un parámetro que en la práctica se considera es causada por iones metálicos divalentes capaces de reaccionar con el jabón para formar precipitados y con ciertos aniones presentes en el agua para formar incrustaciones. En general, la dureza es igual a la concentración de cationes polivalentes del agua [17]. Dentro de la Tabla VI se observa que durante el primer muestreo la dureza presenta una tendencia a la baja a medida que transcurre el tratamiento, sin embargo, durante el muestreo 2 sus valores son casi imperceptibles en las estructuras del final, por lo cual se infiere que las operaciones de mantenimiento y limpieza comprenden una actividad bastante importante para la optimización de los sistemas de tratamiento.

Al igual que la dureza, los cambios presentados en acidez de un muestreo a otro son evidentes, esto podría generarse debido a que la acidez se origina de la oxidación biológica de la materia orgánica. Por lo cual es acertado pensar que, al ser sometida a procesos de limpieza, la planta y sus estructuras pierden la capacidad de promover crecimientos bacterianos (al ser removidos los microorganismos por acciones mecánicas de limpieza y mantenimiento) que contribuyan a la degradación de la materia orgánica, por ende, su medida durante los muestreos 2 y 3 es mucho menor en comparación con el primero de ellos.

La alcalinidad del agua es una medida de su capacidad de neutralizar ácidos. Al igual que los 2 parámetros químicos expuestos anteriormente, la alcalinidad presenta variaciones importantes teniendo un valor aproximado en promedio de $209.20 \mathrm{mg} / \mathrm{l}$ para el primer muestreo. Su valor dentro de los 2 muestreos siguientes es mucho menor y denota que es susceptible a las actividades de limpieza y mantenimiento de la misma manera que la acidez y la dureza.

\section{F. Remoción de carga orgánica en términos $D B O$ y $D Q O$}

La determinación de la Demanda Bioquímica de Oxigeno (DBO) y la Demanda Química de Oxigeno (DQO) en cada una de las estructuras fue la manera de establecer la cantidad de materia orgánica que podía remover el sistema, y de esta manera determinar si el tren de tratamiento desarrolla sus procesos de remoción eficientemente. Estos parámetros son los valores más importantes a la hora de evaluar sistemas de tratamiento. En este estudio, el resumen de los parámetros determinados durante cada ensayo de la Tabla VII, es comparado con los valores establecidos por la resolución 631 del año 2015, en pro de reconocer si el sistema cumple o no con dicha resolución.

Según Romero en [7], la demanda bioquímica de oxígeno DBO es la cantidad de oxígeno que requieren los microorganismos para oxidar (estabilizar) la materia orgánica natural biodegradable en condiciones aerobias. En condiciones normales de laboratorio, esta demanda se cuantifica a $20^{\circ} \mathrm{C}$ y el ensayo estándar se realiza a cinco días de la incubación y se conoce convencionalmente como $\mathrm{DBO}_{5}$. La DQO es útil como parámetro de concentración orgánica en aguas residuales industriales tóxicas a la vida biológica y se puede realizar en solo unas 3 horas. El sistema aerobio de lodos activados es el soporte que posee la planta de tratamiento, y es la estructura donde se presentan las mayores tasas de remoción de carga orgánica. La Tabla VII indica que los valores correspondientes al primer muestreo para la DBO fueron de $936 \mathrm{mg} / \mathrm{l}$ (máxima) y 510 (mínima), $1236 \mathrm{mg} / \mathrm{l}$ (máxima) y $111 \mathrm{mg} / \mathrm{l}$ (mínima) en 
el segundo muestreo y $640 \mathrm{mg} / \mathrm{L}$ (máxima) y $246 \mathrm{mg} / \mathrm{L}$ (mínima) para el tercero. De la misma manera, los valores correspondientes para DQO en el primer muestreo fue de $2662.4 \mathrm{mg} / \mathrm{L}$ (máxima) y $902.4 \mathrm{mg} / \mathrm{L}$ (mínima), $1526.4 \mathrm{mg} / \mathrm{L}$ (máxima) y $617.6 \mathrm{mg} / \mathrm{L}$ (mínima) para el segundo muestreo y $1650 \mathrm{mg} / \mathrm{L}$ (máxima) y $450 \mathrm{mg} / \mathrm{L}$ (mínima).

\begin{tabular}{|c|c|c|c|c|c|c|c|c|}
\hline \multicolumn{9}{|c|}{ TABLA VII } \\
\hline \multicolumn{9}{|c|}{ Muestreo I } \\
\hline Punto de Muestreo & \multicolumn{3}{|c|}{ Demanda biológica de oxígeno, } & \multicolumn{3}{|c|}{$\begin{array}{l}\text { Demanda química de } \\
\text { oxigeno, } \mathrm{DQO}(\mathrm{mg} / \mathrm{L})\end{array}$} & \multirow[t]{2}{*}{$\begin{array}{c}\text { Promedio } \\
\text { DBO(mg/L) }\end{array}$} & \multirow[t]{2}{*}{$\begin{array}{c}\text { Promedio } \\
\text { DQO(mg/L) }\end{array}$} \\
\hline Blanco & \multicolumn{3}{|c|}{$\begin{array}{c}\mathrm{DDU}(\mathrm{mg} / \mathrm{L}) \\
(\mathrm{mgO2} / \mathrm{L})\end{array}$} & \multicolumn{3}{|c|}{ 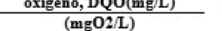 } & & \\
\hline Homogeneizador & 843.00 & 930.00 & 936.00 & 905.60 & 902.40 & 1926.40 & 903.00 & 1244.80 \\
\hline Ecualizador & 588.00 & 723.00 & 573.00 & 1984.00 & 1881.60 & 1836.80 & 1884.00 & 1900.80 \\
\hline Filtro Biológico & 675.00 & 591.00 & 612.00 & 1868.80 & 1612.80 & 1308.80 & 1878.00 & 1596.80 \\
\hline Lodos Activados & 510.00 & 408.00 & 441.00 & 2662.40 & 1980.80 & 2086.40 & 1359.00 & 2243.20 \\
\hline Clarfificador & 177.00 & 213.00 & 111.00 & -22.40 & 22.40 & 99.20 & 501.00 & 33.06 \\
\hline Salida & 180.00 & 258.00 & 108.00 & 121.60 & 105.60 & 54.40 & 546.00 & 93.86 \\
\hline Promedio & \multicolumn{3}{|c|}{8877} & \multicolumn{3}{|c|}{21337.6} & 1178.50 & 1185.42 \\
\hline \multicolumn{9}{|c|}{ Muestreo II } \\
\hline Punto de Muestreo & \multicolumn{3}{|c|}{$\begin{array}{c}\text { Demanda biológica de oxígeno, } \\
\text { DBO(mg/L) }\end{array}$} & \multicolumn{3}{|c|}{$\begin{array}{l}\text { Demanda química de } \\
\text { oxígeno, } \mathrm{DQO}(\mathrm{mg} / \mathrm{L})\end{array}$} & \multirow[t]{2}{*}{$\begin{array}{c}\text { Promedio } \\
\text { DBO(mg/L) }\end{array}$} & \multirow{2}{*}{$\begin{array}{c}\text { Promedio } \\
\text { DQO(mg/L) }\end{array}$} \\
\hline Blanco & \multicolumn{3}{|c|}{$\begin{array}{c}\mathrm{DBBU}(\mathrm{mg} \mathrm{L}) \\
(\mathrm{mgO} 2 / \mathrm{L})\end{array}$} & \multicolumn{3}{|c|}{$\begin{array}{c}\text { oxigeno, } \mathrm{DQO}(\mathrm{mg} / \mathrm{L}) \\
(\mathrm{mg} 02 \mathrm{~L})\end{array}$} & & \\
\hline Homogeneizador & 864.00 & 1041.00 & 813.00 & 1049.60 & 931.20 & 1068.80 & 906.00 & 1016.53 \\
\hline Ecualizador & 1065.00 & 1236.00 & 831.00 & 880.00 & 924.80 & 924.80 & 1044.00 & 909.87 \\
\hline Filtro Biológico & 405.00 & 156.00 & 156.00 & 1001.60 & 1014.40 & 1059.20 & 239.00 & 1025.07 \\
\hline Lodos Activados & 117.00 & 243.00 & 111.00 & 617.60 & 1526.40 & 886.40 & 157.00 & 1010.13 \\
\hline Clarificador & -408.00 & -369.00 & -453.00 & 416.00 & 665.60 & 771.20 & -410.00 & 617.00 \\
\hline Salida & -390.00 & -450.00 & -438.00 & 528.00 & 323.20 & 316.80 & -426.00 & 389.33 \\
\hline Promedio & \multicolumn{3}{|c|}{4530} & \multicolumn{3}{|c|}{14905.6} & 251.67 & 827.99 \\
\hline \multicolumn{9}{|c|}{ Muestreo III } \\
\hline Punto Muestreado & \multicolumn{3}{|c|}{$\begin{array}{c}\text { Demanda biológica de oxígeno, } \\
\text { DBO(mg/L) }\end{array}$} & \multicolumn{3}{|c|}{$\begin{array}{l}\text { Demanda química de } \\
\text { oxigeno, DQO }(m g / L)\end{array}$} & \multirow[t]{2}{*}{$\begin{array}{c}\text { Promedio } \\
\text { DBO(mg/L) }\end{array}$} & \multirow[t]{2}{*}{$\begin{array}{c}\text { Promedio } \\
\text { DQO(mg/L) }\end{array}$} \\
\hline Blanco & \multicolumn{3}{|c|}{$\begin{array}{l}\mathrm{DDO}(\mathrm{mg} \mathrm{L}) \\
(\mathrm{mgO2} / \mathrm{L})\end{array}$} & \multicolumn{3}{|c|}{$\frac{0 \times 1 g e n o, D Q U(m g / L)}{(m g O 2 / L)}$} & & \\
\hline Homogeneizador & \multirow{2}{*}{\multicolumn{3}{|c|}{320.00}} & \multicolumn{3}{|c|}{1650.00} & 200.00 & 1650.00 \\
\hline Ecualizador & & & & & 1574.00 & & 400.00 & 1574.00 \\
\hline Filtro Biológico & \multicolumn{3}{|c|}{382.00} & & 450.00 & & 238.50 & 450.00 \\
\hline Lodos Activados & & 246.00 & & & 470.00 & & 153.80 & 470.00 \\
\hline Clarificador & & 209.00 & & & 985.00 & & 130.80 & 985.00 \\
\hline Salida & & 246.00 & & & 514.00 & & 153.80 & 514.00 \\
\hline Promedio & & 340.5 & & & 940.50 & & 212.82 & 940.50 \\
\hline
\end{tabular}

En la Tabla VII los datos en negrilla pertenecen a los datos que sobrepasan los valores establecidos por la resolución 631 del 2015 (ver Tabla II).

De acuerdo con lo observado en la Tabla VII, en las unidades donde se realizan las fases de pretratamiento, es decir el tanque homogeneizador y tanque ecualizador, los valores de DBO y DQO son bastante altos, por lo que se evidencia un problema de generación de lodo residual excesivo. El enfoque utilizado comúnmente en la reducción carga orgánica y lodo residual es la implementación de tecnologías para el manejo de lodos activados de retorno, que recircula a la corriente principal del biorreactor para su posterior degradación [3]. Sin embargo, varias tecnologías pueden ser aplicadas en la cadena del tratamiento de aguas para reducir la partición neta de carbono en el lodo, incluyendo física (Mecánica, Térmica, Eléctrica), química (Adición de oxidantes o desacoplador), y biológica (mediante depredación bacteriana) [6]. Cabe destacar que la selección de las tecnologías de tratamiento no sólo dependerá del rendimiento de reducción de lodos, sino también sobre los efectos secundarios y costes posibles.

Los costos marginales de operación y mantenimiento del sistema son afectados directamente por el exceso de lodo residual producido en el sistema; puesto que la naturaleza del material biosólido es variable al contener la mayoría de los residuos de las aguas tratadas. La biomasa (lodos) a menudo se somete a cargas de choque y las condiciones operativas de la materia prima pueden conducir a significativos cambios en la composición de los lodos, la calidad del efluente y la producción de biogás [11]. Es decir que el exceso de lodo residual en el sistema es una problemática, la cual se puede tratar teniendo en cuenta que los costos destinados al tratamiento de lodos son superiores al costo de implementar nuevas tecnologías que contribuyan a la disminución en la producción del lodo generado por el tren de tratamiento.

En consecuencia, todo tipo de fallo presentado en el proceso de remoción de carga orgánica tiene repercusión en los procesos subsecuentes a éste y en mayor medida, sobre la calidad del agua con la que es entregada al emisario final. Por lo tanto, el correcto desarrollo de la metodología permite evidenciar la eficiencia de remoción de cada una de las estructuras del tren de tratamiento. La fig. 2 muestra los valores obtenidos para DBO en los 6 puntos muestreados y para los 3 diferentes muestreos realizados. También se indica en la figura el valor máximo permisible según la resolución 631.

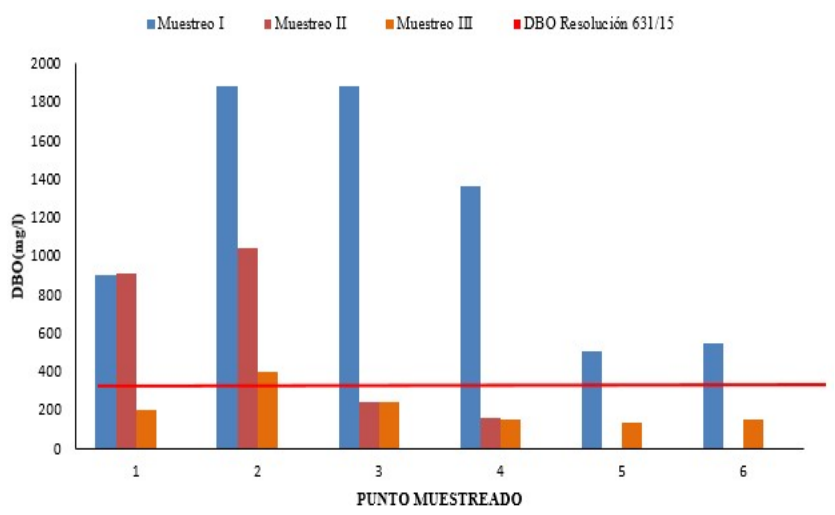

Fig. 2. Valores DBO determinados y DBO resolución 631 año 2015.

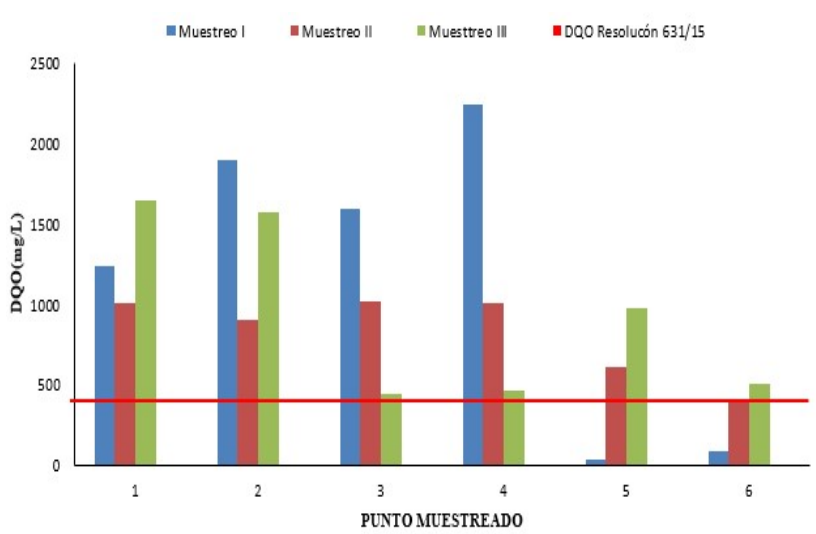

Fig. 3. Valores DQO determinados vs DQO resolución 631 año 2015.

Mediante la comparativa de la resolución 631 del año 2015 con los parámetros más relevantes para la evaluación del sistema (DBO y DQO), se estableció durante el primer muestreo, que este sistema no cumplía con los parámetros máximos establecidos por esta normativa. Sin embargo, las actividades de mantenimiento y limpieza, demostraron ser un buen comienzo en la optimización del sistema, puesto que los resultados presentados en el muestreo 2 y 3 demuestran que el efluente tratado por esta PTAR si cumple con los parámetros establecidos dentro de esta normativa. Como se observa, los procesos subsecuentes a la fase preliminar son afectados de manera directa por el alto contenido de DBO, por lo cual es correcto pensar que una de las maneras de aumentar la eficiencia del tren de tratamiento y poder cumplir a cabalidad 
la normativa es la implementación de sistemas complementarios a los tanques homogeneizador y ecualizador, los cuales contribuyan a la reducción en la producción de lodo residual en pro de aumentar la eficiencia de remoción del sistema en general.

Con la determinación de la DQO se observó que el sistema apenas cumple con la normativa, puesto que el valor establecido para este tipo de industrias es de $400 \mathrm{mg} / \mathrm{l}$. Como se observa en la Fig. 3, la concentración de DQO más alta se presenta en el sistema de lodos activados, punto en el cual el sistema se apoya de procesos microbiológicos para degradar la materia orgánica. Sin embargo, es preocupante observar que, en los procesos subsecuentes a este, los contenidos de DQO siguen siendo altos por lo cual se entiende que, al no remover la materia orgánica en su gran mayoría, el sistema de lodos activados añade una disminución en la eficiencia del clarificador, por tanto, el valor en DQO con el que es entregado el caudal efluente de la planta no cumple con la normativa legal vigente.

\section{CONCLUSIONES}

La temperatura y el $\mathrm{pH}$ son valores indicativos del funcionamiento del sistema por lo que estos deben mantenerse lo más uniformemente estables para lograr las condiciones propias para la remoción de carga orgánica del agua residual.

Parámetros INSITU como sólidos sedimentables, fueron clave para entender la variabilidad en las medidas realizadas al sistema, es decir, recordemos que al sistema se descargan puntualmente las aguas residuales de la industria en períodos de 60 minutos, por lo que es acertado pensar que si se reciben descargas volumétricas cada hora, durante casi 2 horas (tiempo de retención hidráulico del homogeneizador, estructura donde inicia el sistema de tratamiento), se vean alteradas las condiciones hidráulicas por la regulación de caudal y por ende, la medida realizada. De esta manera, y no solo para el tanque homogeneizador sino también para el tanque ecualizador, puesto que estas estructuras comprenden la fase de pretratamiento en la cual se normalizan los caudales entrantes al sistema y las cargas volumétricas del mismo. Debido a la regulación de cargas volumétricas entrantes al sistema realizada por el tanque ecualizador, se evidenció que la fase de pretratamiento cuenta con un buen desempeño en el desarrollo de las actividades de tratamiento debido a su estabilidad en la temperatura y $\mathrm{pH}$, sin embargo, la generación de lodo residual en esta fase comprende un problema que impacta directamente en el costo de operación y mantenimiento del sistema de tratamiento.

El suministro de oxígeno y las concentraciones de OD en tratamientos biológicos aerobios y aguas receptoras de aguas residuales son aspecto de mayor importancia en el diseño, operación y evaluación de plantas de tratamiento de aguas residuales. Todo proceso aerobio requiere de una concentración de OD mayor a $0.5 \mathrm{mg} / \mathrm{L}$. Bajo la determinación del oxígeno disuelto se demostró que el tren de tratamiento desarrolla las condiciones necesarias para la respiración de los organismos aerobios, lo cual demuestra el buen comportamiento de los mecanismos usados para tratar el agua residual efluente de la industria.
El efluente de la planta de producción de bebidas no alcohólicas demostró que la adición de agentes químicos y la tasa de generación de lodo activado frente a las condiciones aerobias del sistema, son el mayor apoyo con el que cuenta la planta para realizar los procesos de degradación en la materia orgánica.

La determinación de bionutrientes, como lo son el nitrógeno y el fósforo, es clave para entender la oxidación bacteriana. De acuerdo con el ciclo del nitrógeno, la forma predominante en aguas residuales es el nitrógeno orgánico, puesto que a medida que el agua se estabiliza las bacterias descomponen el nitrógeno orgánico rápidamente en nitrógeno amoniacal, y si el medio es aerobio mediante oxidación biológica en nitritos y nitratos. Al igual que el nitrógeno, el fósforo recrea las condiciones propias para degradar la materia orgánica; el crecimiento indeseable de algas genera un gran interés por removerlo, puesto que el riesgo de colmatación en los mecanismos de tratamiento puede ser un problema y una causante de baja eficiencia en los procesos de remoción de carga orgánica.

La caracterización fisicoquímica de las aguas residuales contribuyó a determinar si los mecanismos pertenecientes al tren de tratamiento desarrollaban sus operaciones unitarias bajo condiciones eficientes para la reducción de carga orgánica. La disminución de la medida de parámetros como color y turbiedad a través del sistema demuestra que cada estructura dispone de las condiciones mecánicas necesarias para realizar sus procesos de remoción de carga orgánica.

Además de conocer los parámetros INSITU, la caracterización fisicoquímica y los bionutrientes en el agua residual, los parámetros DBO y DQO fueron parte fundamental de este estudio, debido a que estos parámetros también determinan la eficiencia con la que trabajan los equipos pertenecientes al tren de tratamiento.

Para el desarrollo del tratamiento de aguas residuales, las estructuras usadas en el proceso son diseñadas en función de las características hidráulicas, como caudal y/o el tiempo de retención hidráulica; El diseño de dichos mecanismos es función también de las cargas contaminantes entrantes y de los valores máximos permisibles establecidos en la normativa vigente del país. Por lo anterior, y gracias a lo observado en este estudio, es beneficioso para el sistema la implementación de estructuras complementarias al tanque homogeneizador y tanque ecualizador, para la reducción en la producción de lodo residual, puesto que este problema al acarrearse desde las estructuras iniciales del tren de tratamiento conlleva a la pérdida de eficiencia en los procesos subsecuentes a este durante todo el sistema.

\section{AGRADECIMIENTOS}

Producto derivado del proyecto INV-ING-2373 financiado por la Vicerrectoría de Investigaciones de la Universidad Militar Nueva Granada, vigencia 2017. Los autores muestran su gratitud al personal del laboratorio de Calidad de aguas por el soporte técnico ofrecido. 


\section{REFERENCIAS}

[1] Plan nacional de manejo de aguas residuales municipales en Colombia ministerio de ambiente, vivienda y desarrollo territorial Bogotá, D.C. junio de 2004

[2] Z. Vélez. Los Biosólidos: ¿Una solución o un Problema? Producción + Limpia 2 (2), 58-71, 2007.

[3] Q. Wang, W. Wei, Y. Gong, Q. Yu, Q. Li, J. Sun, y Z. Yuan. Technologies for reducing sludge production in wastewater treatment plants: State of the art. Science of the Total Environment Science 587588, 510-521. Doi: 10.1016/j.scitotenv.2017.02.203, 2017.

[4] M. Alemán. Estudio de Impacto Ambiental EXPOST, Planta Norte Embotelladora de Bebidas El Inca, No. de Proyecto: 1047560, cardno forjando el futuro, Información del Documento, 2016. Preparado para: Bebidas Arcacontinental Ecuador, ARCADOR S.A.

[5] D. Azeredo, V. Alvarenga, A. A. Sant'Ana y A. U. Sabaa. An overview of microorganisms and factors contributing for the microbial stability of carbonated soft drinks. Food Research International 82, 136-144. doi: 10.1016/j.foodres.2016.01.024, 2016.

[6] Q. Zhang, J. Hu, D. Lee, Y. Chang, y Y. Lee. Sludge treatment: Current research trends. Bioresource Technology 243, 1159-1172. doi: 10.1016/j.scitotenv.2017.02.203, 2017.

[7] J. A. Romero. Tratamiento de Aguas Residuales. Teoría y Diseño, Bogotá Colombia, Escuela Colombiana de Ingeniería, 2000.

[8] Y. Pan, H. Li, X. Zhang, y A. Li. Characterization of natural organic matter in drinking water: Sample preparation and analytical approaches. Trends in Environmental Analytical Chemistry, 12, 23-30. doi: 10.1016/j.teac.2016.11.002, 2016.

[9] J. A. Rodríguez. Tratamiento anaerobio de aguas residuales. Universidad Del Valle. Cali, Colombia. Recuperado de www.ingenieroambiental.com > tratamiento545

[10] S. S. Marshall, y G. E. Innocentia. Multi-stage EGSB/MBR treatment of soft drink industry wastewater. Chemical Engineering Journal 285, 368 377 doi: 10.1016/j.cej.2015.10.021, 2015.

[11] G. Cuff, A. E. Turcios, E. M. Pajooh, Kujawski, D. Weichgrebe, Rosewinkel. High-rate anaerobic treatment of wastewater from soft drink industry: Methods, performance and experiences. Journal of Environmental Management 220, 8-15. doi 10.1016/j.jenvman.2018.05.015, 2018.

[12] S. V. Jadhav, S. S. Haramkar, A. R. Kamble, y B. N. Thorat. Insights into dewatering and characterization of the waste activated sludge. Journal of the Taiwan Institute of Chemical Engineers 000, 1-7. doi: 10.1016/j.jtice.2017.11.035, 2017.

[13] J. L. Zou, G. R. Xu, K. Pan, W. Zhou, W. Dai, Xue., Zhang, Di., Y. C. $\mathrm{Hu}$, y M. Ma. Nitrogen removal and biofilm structure affected by $\mathrm{COD} / \mathrm{NH} 4+-\mathrm{N}$ in a biofilter with porous sludge-ceramsite doi: 10.1016/j.seppur.2012.03.019, 2012.

[14] M. A. Latif, C. M. Mehta, y D. J. Batstone. Low pH anaerobic digestion of waste activated sludge for enhanced phosphorous release. Water Research 81 (2015) 288-293, 2015.

[15] J. V. Arboleda. Teoría y práctica de la purificación del agua, Bogotá Colombia, Acodal. Asociación Colombiana de Ingeniería Sanitaria y Ambiental, 1992.

[16] Y. Wen, Y. Mao, y X. Wang. Application of chromaticity coordinates for solution turbidity measurement. Measurement 130 (2018) 39-43 doi: 10.1016/j.measurement.2018.07.0817, 2018.

[17] Instituto de Hidrología, Meteorología y Estudios Ambientales Ministerio de Ambiente, Vivienda y Desarrollo Territorial - República de Colombia.

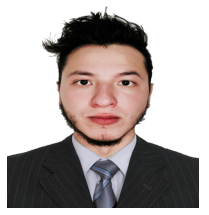

Fernando Velasco Rueda. Nació en Pitalito, Colombia el 25 de mayo de 1995. Es aspirante a optar al título de Ingeniero Civil por la Universidad Militar Nueva Granada. Ejerció actividades de auxiliar de investigación. Culminó sus estudios de bachiller básico de primaria y secundaria en el Instituto San Juan de Laboyos.

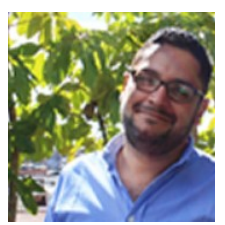

Andrés Felipe Molano Guarín. Microbiólogo Industrial (Universidad Javeriana), con énfasis en Bioprocesos asociados a temas de contaminación hídrica y edáfica. Especialista en Ingeniería y Tecnología de Procesos Biológicos (Universidad Agraria de la Habana) y Especialista en Manejo Integrado del Medio Ambiente (Universidad de los Andes). Magister en Gestión Ambiental (Universidad Javeriana). Experiencia en Plantas de Tratamiento de Residuos Sólidos Municipales - Tratamiento Biológico de Aguas Residuales y Descontaminación de Suelos en el área de Investigación y Desarrollo a nivel de Procesos de Compostaje y Lombricultura; Manejo ambiental en Plantaciones de Flores Tipo exportación en las áreas del manejo de Residuos Sólidos y Biofertilizantes. Profesor Asociado del Programa de Ingeniería Ambiental Universidad ECCI - Colombia Director de Grupo de Investigación GADES (Gestión Ambiental y Desarrollo Sostenible); Profesor Catedrático de la Universidad Sergio Arboleda y Universidad Militar Nueva Granada en área de Ingeniería Ambiental. Asistente de investigación.

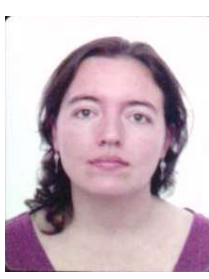

Laura Mariela Pramparo. Nacida en Río Cuarto (Argentina), se graduó de Ingeniera Química en la Universidad Nacional de Río Cuarto (Argentina) en 2001. Obtuvo el Diploma De Estudios Avanzados (DEA) en la Universitat Rovira i Virgili (España) en el año 2005 y su posterior Doctorado en Ingeniería Química y de Procesos en la Universitat Rovira i Virgili en 2008. Trabajó Como becaria de investigación en la Universidad Nacional de Río Cuarto y en la Universitat Rovira i Virgili. Fue investigador visitante en la Universitè de Nantes (Francia) entre 2005 y 2006 y en la University of Windsor (Canadá) en el año 2007. Se desempeñó como investigador postdoctoral en la Universitat Rovira $i$ Virgili (España) en 2009 y como investigador postdoctoral en la Universitat Autónoma de Barcelona (España) en 2010. Desde el año 2012 se desempeña como docente investigador en la Universidad Militar Nueva Granada (Colombia). Actualmente es la coordinadora académica de posgrados de la facultad de ingeniería de dicha universidad, la cual se ubica en la cra 11\#10180 de la ciudad de Bogotá. ORCID: http://orcid.org/0000-0001-6263-5800. 